\title{
2
}

\section{Harmonization of Personal and Organizational Purpose}

\author{
Carlos Rey and Ivan Malbašić
}

Like most companies, Unilever has lived under a set of corporate values that have been the mainstay of the organization for decades. In 2014, inspired by these principles, the company launched a program called "Brand Purpose" with the intent of transmitting the corporate purpose across all the brands. In the same year, the company started another program called "Personal Purpose" in which it encouraged the employees, all over the world, to find their own meaning in the work they did.

Today, more than half of the Unilever brands have implemented Brand Purpose and more than 30,000 employees have participated in the personal purpose program. The internal results of the company have indicated that those brands in which purpose was implemented grew twice as fast as those which did not. And the employees who implemented their personal purpose had less burnout, greater productivity, and more innovation.

As we have seen at Unilever and many other companies, evidence from the field shows that purpose is being infused increasingly at both the corporate and the individual levels. Behind this practice is the idea of connecting individual purpose to that of the organization-what we refer to in this book

\footnotetext{
C. Rey $(\bowtie)$

Universitat Internacional de Catalunya,

Barcelona, Spain

e-mail: carlosrey@uic.es
}

I. Malbašić

Faculty of Organization and Informatics, University of Zagreb, Zagreb, Croatia e-mail: ivan.malbasic@foi.hr 
as unity-making its way into companies in what clearly seems to be a constant upward trend. In this chapter, we are going to see the essence of this connection and consider its fundamental nature, along with the processes that ensure it remains vibrant over time. Built upon recent research on plural identity and authenticity at work, a two-sided view of purpose is developed, suggesting the harmonization of personal and organizational purposes across two basic dimensions: purpose fluidity and purpose synergy. The first is related to the exchange of meaningful representations between personal and organizational purposes. The second relates to the way personal and organizational purposes partly or fully integrate with each other.

\section{Connecting the Two Sides of Purpose}

Scholars typically refer to purpose from a perspective that moves from the organization to the individual, and so organizations typically define a purpose, then communicate it to their employees to offer a sense of purpose in their work. With this approach, employees need to incorporate the purpose of the organization into their own viewpoint in order to give higher meaning to their efforts. Consequently, individuals see their work as more than just a simple task, understanding it as something that contributes significantly to a higher cause. To the extent that employees internalize the organizational purpose, it affords them an opportunity to transcend the task themselves, giving them a more meaningful understanding of their work. In this regard, the organization's ultimate purpose "provides" a sense of purpose to its employees.

We can see this, for example, in the anecdote about the well-known NASA janitor who said, "I'm not mopping floors, I'm putting a man on the moon." The study of this case and others investigates how leaders and their rhetoric motivate employees to internalize an organization's purpose. Like this study, much of the traditional research around purpose over recent decades has been based on this notion that purpose flows from the organization to the individual.

However, there is another side of purpose, an equally important and impactful side, that has been much less explored in management literature. It is the perspective that argues purpose must also be created and moved "from the individual to the organization." In this perspective, individuals derive a sense of meaning in their work from their personal purpose. And this plays a crucial role in the development of meaning because one's own purpose is an enormous source of motivation. It endows any task with deeper meaning, while reinforcing the individual's value system. When individuals approach their work from personal purpose, their aspirations are encouraged, and they 
become more energized in their current roles. ${ }^{2}$ Personal purpose "empowers individuals with timeless strength in the midst of change." ${ }^{3}$ More than merely fulfilling a task or doing a job, employees feel they are "being themselves at work," incorporating into the organization their unique purpose in life.

Some may think that this is attainable only for those in high positions or in vocational professions, but it is not. The work of ISS Facility Services in fostering purpose development in their employees, for instance, offers convincing examples of how one can create a higher sense of purpose even for mundane work. This is the case of the ISS cleaning professional, who works in a Næstved Municipality school in Denmark. She reflects upon her passion for serving others through her statement: "By keeping the school clean, I help the students focus on learning and developing their talents-while I do the same in my job every day." Or consider a general worker in charge of cleaning and changing the bed linen at the Tzu Chi Hospital in Taiwan who expressed his work as: "Helping patients on the way to recovery with a clean sheet." These examples challenge the understanding that some tasks have less personal meaning than the work found in professions such as medicine or education, ${ }^{4}$ and indicate that finding meaning at work is not a matter of the kind of work you do but, rather, of the kind of person you want to be.

Such examples of purpose at work, seen in the employees referred to above, can be as powerful and meaningful as "putting a man on the moon" was for the NASA janitor. By connecting the personal purpose with work, people find a much greater understanding of the transcendence of their efforts, and more importantly, reinterpret those efforts over time.

The combination of these two notions of purpose- "from organization to individual" and "from individual to organization"-offers a more comprehensive view of the full potential of purpose in organizations. This duality of purpose not only suggests that a company "inspire" the individual, but also that a company "is inspired" by the personal purpose of each of its employees. Indeed, the purpose of the organization can provide guidance for each individual, but it should not replace the experience of every employee to discover his or her personal purpose at work.

This is consistent with research that has "demystified charismatic/transformational leadership" by demonstrating that, in purpose-driven organizations, individuals connect their work not only to the collective purpose, but also to their own personal purpose. ${ }^{5}$ This can also be seen in the research regarding plural work identity harmonization. ${ }^{6}$ When harmonizing purpose, individuals connect the corporate purpose with their personal purpose, finding plural sources of meaning and a sense of purpose in their daily work. Following this framework (see Table 2.1), harmonization enhances the understanding of 
Table 2.1 Harmonizing purpose in organizations

\begin{tabular}{|c|c|c|}
\hline $\begin{array}{l}\text { Purpose } \\
\text { harmonization }\end{array}$ & Description & Examples \\
\hline Fluidity & $\begin{array}{l}\text { Reinforcement between } \\
\text { personal and organizational } \\
\text { and purpose }\end{array}$ & $\begin{array}{l}\text { - Providing employees with } \\
\text { representations of impact to the } \\
\text { organization and its beneficiaries } \\
\text { - Helping employees reflect on their } \\
\text { purpose at work } \\
\text { - Acknowledging the purpose of } \\
\text { each employee }\end{array}$ \\
\hline Synergy & $\begin{array}{l}\text { Intersection between personal } \\
\text { and organizational purpose }\end{array}$ & $\begin{array}{l}\text { - Hiring for fitting into the } \\
\text { organizational purpose } \\
\text { - Discovering purpose that already } \\
\text { exists in organizational members } \\
\text { - Designing career paths around the } \\
\text { connection between personal and } \\
\text { organizational purpose }\end{array}$ \\
\hline
\end{tabular}

how personal and organizational purposes support each other by dynamically exchanging meaning (purpose fluidity) as well as intersecting it to enrich each other (purpose synergy). This requires overcoming the "myth of two separate worlds" in which work identities are completely disconnected from non-work identities. $^{7}$ In the two-sided notion of purpose, individuals authentically receive meaning from the purpose of the organization and the organization authentically receives meaning from the purpose of each employee. It is related to what some call the "ideological currency" that enhances the psychological contract between the employee and the organization. ${ }^{8}$

\section{Nurturing Fluidity}

Purpose fluidity explains how individuals and organizations exchange meaningful representations of purpose at work, enhancing the sense of purpose when flowing dynamically between personal and organizational purposes. In other words, fluidity is not just using one representation of purpose (personal or organizational), but combining both at the same time, flowing from the personal to the organizational and vice versa, as is shown in Fig. 2.1. Fluidity then is based on what an organization's purpose means to the individual as well as what the individual's purpose means to the organization.

Fluidity is a powerful source of meaning and personal flourishing. It occurs when employees see and experience that contributing to the corporate purpose helps them to develop their personal purpose in life. Following the previous example, fluidity can be illustrated by such examples as "helping to put a 


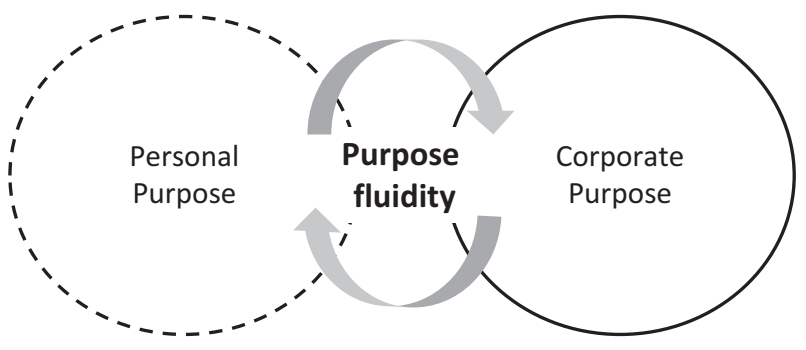

Fig. 2.1 Purpose fluidity

man on the moon reinforces my personal purpose of making an impact on society." Of course, purpose fluidity does not come by simply elaborating creative axioms, but from these connections becoming profoundly ingrained in the minds and hearts of individuals.

We have seen many practices that foster purpose fluidity. This is the case, for example, of Novo Nordisk, a company that makes medicines for diabetics, and requires that all new employees spend a day with a diabetes patient. ${ }^{9}$ It is also the case for ISS Facility Services, where top managers spend one day a year performing frontline positions, such as cleaning or maintenance, in the premises of their clients. These practices are a source of what some call "a beneficiary contact," ${ }^{10}$ helping individuals to experience and gain greater consciousness of their organization's purpose.

We could offer many testimonies of people who, with pride and gratitude, refer to how such practices have helped them become both better persons and better citizens. Indeed, one of the unmistakable signs of a purpose-driven company is that, in an ordinary and sometimes unnoticed way, it positively influences the families and personal relationships of their employees. By encouraging various representations of the corporate purpose, employees find greater sources of meaning from which to choose. What does the purpose of the company in which I work mean to me? And how does it help me in the development of my purpose? These are central questions in the workshops at Bimbo, for example, where 130,000 employees reflect upon their personal purpose along with that of the organization.

Besides, fluidity is related to the question: what do various individual employee purposes mean for the company? Consider, for example, the case of KPMG. After defining the corporate purpose as "inspiring confidence and empowering change" the company did not embark on a typical slogan-based communication campaign. Instead, partners and managers, with the company's purpose as a backdrop, were encouraged to connect compelling stories and personal examples about their own purpose. Following this, the rest of the employees were invited to do the same, combining reflections on the cor- 
porate purpose with sharing their own accounts of how they believed they were making a difference. As a result of maintaining this practice over time, recruitment improved, employee turnover decreased, and the company climbed 31 places on Fortune's list of the 100 Best Companies to Work For. ${ }^{11}$

Fluidity requires that companies recognize the relevance of each employee's purpose. It means placing the person at the center of the organization and appreciating his or her dignity and uniqueness. In this way, fostering fluidity at scale is a means to embrace diversity in organizations, as "the idea of embedding plurality in purpose is that we share a common humanity, and people are kept at the heart of the business enterprise." 12

Consider, for example, the business philosophy of the German company $d m$-drogerie markt ${ }^{13}$ expressed by the motto: "Here I'm a person. Here I'm shopping!" Initially, it referred to their customers, but naturally started to be used to refer to the employees as well: "Here I'm a person. Here I'm working!" These two simple sentences are the backbone of dm's business. They express the purpose of $d m$, that is, respect for people, or more precisely, respect for the value and uniqueness of each individual. $d m$ explains this motto by stating that it is a commitment to put the individual at the center of everything, whether he/she is a customer or a worker, offering to every person the right to emphasize his/her individuality. For $d m$, embracing diversity is much more than a matter of quotas, but of respecting each individual as he or she is. ${ }^{14}$

Fluidity allows individuals to connect personal and organizational purposes without necessarily identifying them. This is especially relevant for the many positions and professions that are not commonly thought of as professional, such as the worker in a factory or the cashier at a supermarket. This is because fluidity is based on concordance, ${ }^{15}$ and refers to the extent to which the organizational purpose can be used by employees to express their authentic interests and values.

We observed this reality in the practice of a store manager at Decathlon, which he called "the 15 minutes of purpose" meeting. At the beginning of each day, store employees gathered and exchange tales and anecdotes from the previous day about how they promoted the corporate purpose of "making sport accessible to many" (e.g., how an employee helped advise a customer on how to best prepare for a triathlon, or helped another customer find the best bicycle for his particular needs). However, we saw in many cases, that more enthusiasm was expressed for stories not related to sports but rather, to other themes that were significant to the one explaining it (e.g., "I helped a young boy find a good present for his girlfriend"; "I made a sad client have a good time shopping in the store"). Speaking with the employees, we observed that, even the ones who were not very passionate about sports, by making mean- 
ingful connections of their personal purposes with the company's purpose, gained a better sense of purpose in their activities.

Keeping the dynamic fluidity "alive" is about what some have called "making every-day-work meaningful." ${ }^{16}$ And since fluidity goes in two directions, it is much like friendship or trust. We can trust someone, but if we do not feel that person's corresponding trust in us, our own trust will be short lived. The same happens with purpose fluidity. If individuals do not see that the organization values their personal purpose in life, sooner than later they will become distant to their organization's purpose and purpose fluidity will be lost.

\section{Facilitating Synergy}

When a company hires someone, it hires much more than a particular set of knowledge and skills. A person's greatest potential lies in his or her personal life's purpose, in the enthusiasm and determination through which he or she wants to contribute to the betterment of society. It is a desire that exceeds the field of labor, but does not at all exclude it. The desire we all have to make a difference and contribute to make a better world is a company's true source of innovation and creativity, and represents the key to our willingness to constantly improve ourselves, whether that be in knowledge or skill. The greatest asset of an organization is the personal purpose of each individual and one's aspiration to be useful and to leave a mark. Many companies are well aware of this reality and harness it. Consider, for example, how the Indian IT services HCL Technologies promotes what they call the Employee Passion Indicator Count (EPIC), which is used to identify the key "passions" of employees and to steer them toward jobs where these could be put to best use. ${ }^{17}$

Purpose synergy is found at the junction of company purpose and personal purpose (see Fig. 2.2). Purpose synergy is the place of overlap between the

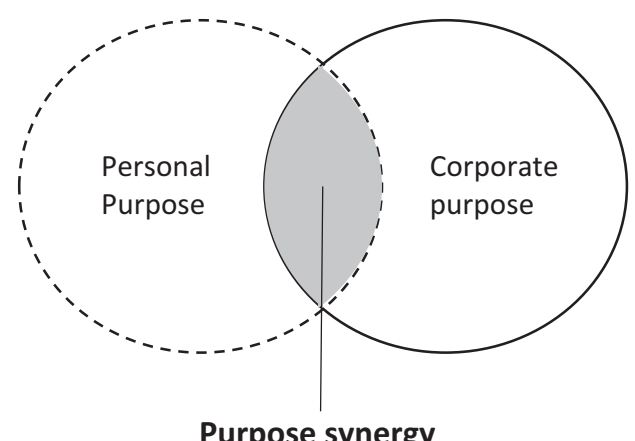

Purpose synergy

Fig. 2.2 Purpose synergy 
company and the individual, where the interests of the company and its individual employees combine to reach its most perfect form. It is not a simple exercise in self-development, one that is disconnected from the company purpose. Nor is it an exercise in indoctrinating employees with the corporate purpose. It is not about training courses or communication campaigns. It is about channeling the potential of the person's purpose within the context of the company's purpose. Purpose synergy reveals what the person best brings to the company and vice versa. Thus, synergy occurs in part of the company purpose as well as the individual's life purpose.

Consider, for example, the case of Alpha Omega, a high-tech medical device company in Israel devoted to the purpose of improving peoples' lives. Its founders, Imad and Reem Younis, have been committed, from a very young age, to the purpose of developing work environments where Jews and Arabs can work together in harmony. And in leading their company, they incorporate this personal purpose into the corporate purpose. They hire Jews and Arabs alike, employees who not only excelled at their work, but also share in a dream of creating inclusive work environments. At Alpha Omega, the purpose of improving peoples' lives is defined as "Joined together to improve people's life," creating a strong synergy between organizational purpose and the personal purpose of the founders and employees. As Imad has said, "it is like putting my soul inside the company's soul." 18

When organizations develop purpose synergy, employees find more energy and sense of purpose in their work, and feel like "putting their soul into their work." One way to create synergy is by recruiting employees who have personal affinities with the organizational purpose. Especially when creating new companies, this is one of the most powerful ways to create synergy. Another way, especially relevant in the case of existing employees, is to find and foster a purpose that already exists in the organization. Following the principle of "If it is real, it is possible," it is about "finding examples of people or teams within the organization that exceed the norms, examining the purpose that drives their excellence, and then imagining it imbuing the entire workforce." ${ }^{19}$

\section{The Joint Effect of Fluidity and Synergy}

Fluidity and synergy have common drivers, but are different from each other. Fluidity allows the connecting of personal and organizational purposes without necessarily identifying solely with one or the other. With synergy, however, both personal and organizational purposes partly or fully identify with one another, meaning that the organization incorporates the purpose of the 
individuals and vice versa. We could say that fluidity helps organizational and personal purposes get closer, while synergy integrates them. Fluidity helps to create unity, synergy is the result of the unity itself.

But together with these fundamental practices, synergy must be reinforced and sustained by constant fluidity. Because if employees do not flow at work, even the existing synergy can be snuffed out. Fluidity helps not only to create synergy, but also to sustain it and keep it alive. This explains why, despite recruiting people who have a great affinity for the corporate purpose, synergy will not occur if employees, for example, see that the organization is not true to its purpose or if they feel that the organization does not respect the dignity and uniqueness of employees' purpose. And this can happen even in professional jobs, like those of doctors or teachers, where purpose synergy usually comes as part and parcel with the profession.

In short, the phenomenon of shared purpose is an inspiration for both individuals and organizations. Employees should continually seek what is, or what could inspire them at work, embracing a deeper understanding - that the purpose of their work is much more than earning a salary or having good working conditions. Companies, on the other side, should see their employees not just as human capital or means of return, but as individuals with invaluable potential with different ideas and personalities that provide an inexhaustible source of creativity. And the responsibility for connecting purpose lies with both-organizations need to be truly interested in what their employees want to contribute to the world, while at the same time employees should see their work as a way to fulfill collective aspirations and dreams.

\section{Notes}

1. Carton, A. M. (2018). "I'm not mopping the floors, I'm putting a man on the moon": How NASA leaders enhanced the meaningfulness of work by changing the meaning of work. Administrative Science Quarterly, 63(2), 323-369.

2. Craig, N., \& Snook, S. (2014). From purpose to impact. Harvard Business Review, 92(5), 104-111.

3. Covey, S. R. (1989). The 7 habits of highly effective people: Powerful lessons in personal change. New York, NY: Fireside/Simon \& Schuster.

4. Ariely, D., Kamenica, E., \& Prelec, D. (2008). Man's search for meaning: The case of Legos. Journal of Economic Behavior \& Organization, 67(3-4), 671-677.

5. Bono, J. E., \& Judge, T. A. (2003). Self-concordance at work: Toward understanding the motivational effects of transformational leaders. Academy of Management Journal, 46(5), 554-571. 
6. This framework explains that authenticity at work occurs in two sequential processes. The first, synchronization, is about the way individuals understand their own work within the available organizational identities (e.g., "putting a man on the moon"). The second, harmonization, is related to how individuals understand their work combining self-identities (e.g., "I want to make an impact on society") and organizational identities. Harmonization enhances the understanding of how the work and self-identities dynamically exchange meaning ("identity fluidity") and how they enrich each other ("identity synergy"). Caza, B. B., Moss, S., \& Vough, H. (2017). From synchronizing to harmonizing: The process of authenticating multiple work identities. Administrative Science Quarterly, 63(4), 703-745.

7. Ramarajan, L., \& Reid, E. (2013). Shattering the myth of separate worlds: Negotiating nonwork identities at work. Academy of Management Review, 38(4), 621-644.

8. Thompson, J. A., \& Bunderson, J. S. (2003). Violations of principle: Ideological currency in the psychological contract. Academy of Management Review, 28(4), 571-586.

9. Birkinshaw, J., Foss, N. J., \& Lindenberg, S. (2014). Combining purpose with profits. MIT Sloan Management Review, 55(3), 49.

10. Grant, A. M. (2012). Leading with meaning: Beneficiary contact, prosocial impact, and the performance effects of transformational leadership. Academy of Management Journal, 55(2), 458-476.

11. Quinn, R. E., \& Thakor, A. V. (2018, July-August). Creating a purposedriven organization. Harvard Business Review, pp. 78-85.

12. Hollensbe, E., Wookey, C., Hickey, L., George, G., \& Nichols, C. V. (2014). Organizations with purpose. Academy of Management Journal, 57(5), 1227-1234.

13. One of the largest drug chains in Central and South-Eastern Europe, established in 1973 in Karlsruhe, Germany, that sells cosmetics, healthcare items, household products, and health food.

14. There are many interesting aspects of purpose fluidity at $\mathrm{dm}$. One fascinating part is the story about the founder and owner of $\mathrm{dm}$. Just when everybody thought that he had done everything possible for his "capitalism with a human face," the world was astonished to learn that he had decided to leave his fortune not to his children (and he had seven!), but to give it away for charitable purposes. This resonates even more when one realizes that his wealth is estimated at more than a billion euros. This amazing decision was for him reasonable, as it was based on a principle deeply ingrained in his personal purpose: "There is no shame in becoming rich, but it is a shame to die rich."

15. Sheldon, K. M., \& Elliot, A. J. (1999). Goal striving, need satisfaction, and longitudinal well-being: The self-concordance model. Journal of Personality and Social Psychology, 76(3), 482. 
16. Almandoz, J., Lee, Y., \& Ribera, A. (2018). Unleashing the power of purpose: 5 steps to transform your business, IESE Insight, 37, Second Quarter, 44-51.

17. Birkinshaw, J., Foss, N. J., \& Lindenberg, S. (2014). Combining purpose with profits. MIT Sloan Management Review, 55(3), 49.

18. https://www.youtube.com/watch?v=ejLoKiBzL94\&t=237s. Retrieved January 30, 2019.

19. Quinn, R. E., \& Thakor, A. V. (2018, July-August). Creating a purposedriven organization. Harvard Business Review, pp. 78-85.

Open Access This chapter is licensed under the terms of the Creative Commons Attribution 4.0 International License (http://creativecommons.org/licenses/by/4.0/), which permits use, sharing, adaptation, distribution and reproduction in any medium or format, as long as you give appropriate credit to the original author(s) and the source, provide a link to the Creative Commons licence and indicate if changes were made.

The images or other third party material in this chapter are included in the chapter's Creative Commons licence, unless indicated otherwise in a credit line to the material. If material is not included in the chapter's Creative Commons licence and your intended use is not permitted by statutory regulation or exceeds the permitted use, you will need to obtain permission directly from the copyright holder.

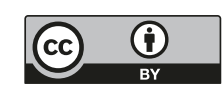

